\title{
Assessment of the changes in extreme vulnerability over East Asia due to global warming
}

\author{
Min-Hee Lee • Chang-Hoi Ho • Jinwon Kim • \\ Chang-Keun Song
}

Received: 19 March 2010 / Accepted: 2 October 2011 / Published online: 23 November 2011

C The Author(s) 2011. This article is published with open access at Springerlink.com

\begin{abstract}
A number of indices have been employed to describe weather extremes on the basis of climate regimes and public concerns. In this study, we combined these traditional indices into four groups according to whether they relate to warm $\left(\mathrm{T}_{\mathrm{warm}}\right)$, cold $\left(\mathrm{T}_{\text {cold }}\right)$, wet $\left(\mathrm{P}_{\text {wet }}\right)$, or dry $\left(\mathrm{P}_{\text {dry }}\right)$ extremes. Analysis of the combined indices calculated for the daily temperatures and precipitation at 750 meteorological stations in Korea, China, and Japan for $1960 \mathrm{~s}-2000$ s shows increasing trends in $\mathrm{T}_{\text {warm }}$ and $\mathrm{P}_{\text {dry }}$ events and decreasing trends in $\mathrm{T}_{\text {cold }}$ events in recent decades, particularly in the northern part of East Asia. A notable regional variation is an increase in the $\mathrm{P}_{\text {wet }}$ events in the Korean Peninsula. We applied the same analysis to a 200-year global climate model simulation for 1900-2099 using the National Center for Atmospheric Research-Community Climate System Model 3. During the 20th century, the changes in $\mathrm{T}_{\text {warm }}$ and $\mathrm{T}_{\text {cold }}$ calculated from the model data are largely consistent with those calculated from the observations, especially in northern East Asia. The model projections for the 21 st century indicate statistically significant increasing $T_{\text {warm }}$ and decreasing $\mathrm{T}_{\text {cold }}$ trends in extreme events over the region. Results obtained from historical archives and model simulations using our combined weather extreme indices suggest that northern East Asia will be subject to increased warm and dry extremes and the Korea Peninsula will experience more wet extremes.
\end{abstract}

M.-H. Lee • C.-H. Ho

Computational Science and Technology, Seoul National University, Seoul, South Korea

C.-H. Ho $(\square)$

Climate Physics Laboratory, School of Earth and Environmental Sciences, Seoul National University, Seoul 151-742, South Korea

e-mail: hoch@cpl.snu.ac.kr

J. Kim

Department of Atmospheric and Oceanic Sciences, UCLA, Los Angeles, CA, USA

C.-K. Song

Climate Research Division, National Institute of Environmental Research, Incheon, South Korea 


\section{Introduction}

Extreme weather events take a heavy toll on human lives, crops, water supply, industries, and ecosystems. Weather extremes, rather than changes in the mean climate, are the most consequential impact of global climate change (Kim 2005; Trenberth et al. 2007), though these extreme events may significantly respond to small changes in the mean climate (Katz and Brown 1992). Assessing the changes in extremes associated with recent climate change is thus one of the most important concerns of climate research.

The impact of climate change on a variety of weather extremes has been examined in a number of studies for North America (e.g., Karl et al. 1996; DeGaetano 1996), Europe (e.g., Heino et al. 1999; Osborn and Jones 2000), and East Asia (e.g., Iwasima and Yamamoto 1993; Zhai and Pan 2003, Park et al. 2011). In particular, East Asia has experienced intense natural disasters accompanied by extreme weather episodes in recent decades. As examples, record-breaking rainfall from typhoon 'Rusa' in 2002 resulted in a number of human casualties and economic losses of over 5 billion US dollars in Korea (c.f., Kim et al. 2006; Park and Lee 2007), and in September 2006, a heat wave occurred over an extended period across most of China with daily maximum temperatures well over $35^{\circ} \mathrm{C}$ (Ding et al. 2009). Such weather extremes cause substantial damages to the heavily concentrated industries and densely populated areas in East Asia. Reducing the damages inflicted by weather-related natural disasters is a priority in the region, and current disaster prevention plans include monitoring weather extremes and investigating the detailed mechanisms that produce such extremes.

Most previous studies have examined the characteristics of a single extreme weather event such as a typhoon, heavy rainfall, or warm/cold incident (Kim et al. 2005; Peterson and Manton 2008; Alexander and et al. 2006; Park et al. 2011). Single-event study is essential, because each event has some unique distribution or other characteristic. However, it is human nature for people to think that these extreme events happen only "elsewhere" and will not occur where they live even though global warming is changing weather worldwide. To provide perspective on the potential for extreme weather events, we here introduce a set of new indices created by integrating the existing various extreme-weather indices. Our new indices may help individuals to see the larger impact of various weather extremes and even the particular vulnerability of their own residential area to weather extremes.

We also investigated historical changes in extreme vulnerability, and modeled projected weather extremes expressed in the new indices, using observations and General Circulation Model (GCM, also known as Global Climate Model) simulations. The gridded values of our new group indices provide geographic visualization of regional and local vulnerabilities to extreme weather, information potentially very useful to both residents and policy makers.

This paper is organized as follows. Section 2 describes the dataset and methodology used for grouping indices to integrate various impacts of extremes. Sections 3 and 4 discuss changes in the extreme vulnerability over East Asia using these newly suggested indices, from observation and climate model projection, respectively. A summary is given in Section 5 .

\section{Data and method}

\subsection{Data}

We analyzed the observed daily precipitation (PRCP), maximum temperature (TX), and minimum temperature (TN) over East Asia to assess the characteristics of historical extreme 
events. The daily datasets analyzed were obtained from meteorological stations operated by the governmental meteorological administrations of Korea, China, and Japan. The analysis period covers the recent five decades (1960s-2000s); the beginning and ending years of individual records vary according to stations and variables, but all selected stations included the records for 1970-1999. For data quality control, stations that had missing data for more than seven consecutive days or for a total of 30 days during the five decades were excluded. Although we could not check the individual accuracy of each station used, the data did show a spatially coherent pattern in the variation of each dataset, which we believe confirms the reliability of data used in this study (figure not shown). After filtering out stations that did not meet our quality control criteria, we collected the data from 607 Chinese, 118 Japanese, and 25 Korean stations, for a total of 750 meteorological datasets. The final list of stations included in the analysis is presented in Table 1.

To project the changes in future extreme weather, we performed a future climate simulation using a coupled GCM (CGCM), the National Center for Atmospheric Research (NCAR) Community Climate System Model 3 (CCSM3; Collins et al. 2006), in conjunction with the Intergovernmental Panel on Climate Change (IPCC) Special Report on Emissions Scenarios (SRES) A2, A1B, and B1 (Nakicenovic et al. 2000) for projecting the climate in the 21 st century (i.e., 2000-2099). The CCSM3 has been configured with T85 (approximately $1.4^{\circ} \times 1.4^{\circ}$ ) in the horizontal and 26 layers in the vertical. These scenarios assume that the carbon dioxide $\left(\mathrm{CO}_{2}\right)$ emission in the end of the 21 st century will

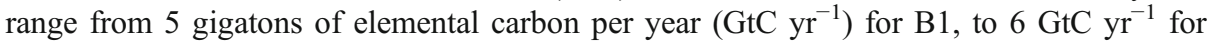

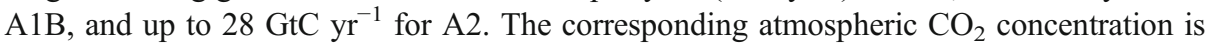
expected to range from 500 to 900 parts per million by volume (ppmv). In addition, a 20th century experiment (20C3M) for the period 1900-1999 was also performed for comparison with observations; forcing agents in this experiment were the historical records of greenhouse gases.

To confirm the reliability of the projected changes in this study, we additionally analyzed several coupled GCMs that participated in IPCC AR4. Among the 25 IPCC AR4 models, six included the required daily maximum and minimum temperature: BCCR-BCM2.0, CCCMA-CGCM3.1 (T42), CNRM-CM3, CSIRO-MK3.0, CSIRO-MK3.5, GFDL-CM2.0. More detailed descriptions of these six models are found in Table 2.

\subsection{Indices for extreme vulnerability}

To evaluate the integrated impact of several weather extremes, we designed four simplified new indices by combining various indices previously used. Table 3 compiles the definitions of the single, previously defined, indices which were adapted from the Expert Team on Climate Change Detection, Monitoring and Indices (ETCCDMI) and have been widely used as tools to estimate and monitor changes in extremes (Peterson and Manton 2008; Alexander et al. 2006). Because combining indices of contrasting characteristics (e.g., warm extreme variables versus cold extreme variables) is likely to result in the loss of

Table 1 Numbers of Chinese, Korean, Japanese, and total meteorological stations used for calculating daily maximum temperature (TX), daily minimum temperature (TN), and daily precipitation (PRCP)

\begin{tabular}{llll}
\hline & TX & TN & PRCP \\
\hline China & 539 & 549 & 607 \\
Korea & 25 & 24 & 25 \\
Japan & 118 & 118 & 118 \\
Total & 682 & 691 & 750 \\
\hline
\end{tabular}


Table 2 Description of the coupled global circulation models (CGCMs) used in this study

\begin{tabular}{llll}
\hline Model & Originating Group & Country of origin & Atmospheric resolution \\
\hline BCCR-BCM2.0 & BCCR & Norway & T63L31 \\
CCCMA-CGCM3.1 (T47) & CCCMA & Canada & T47L31 \\
CNRM-CM3 & CNRM & France & T63L45 \\
CSIRO-MK3.0 & CSIRO & Australia & T63L18 \\
CSIRO-MK3.5 & CSIRO & Australia & T63L18 \\
GFDL-CM2.0 & GFDL & USA & $2.5^{\circ} \times 2^{\circ}$ L24 \\
CCSM3 & NCAR & USA & T85L26 \\
\hline
\end{tabular}

inherent characteristics of individual indices, we grouped a total of 24 indices into 4 categories according to their distinctiveness such as warm, cold, wet, and dry, as shown in Table 3. The warm extreme group $\left(\mathrm{T}_{\text {warm }}\right)$ contains the annual maximum of daily maximum/minimum temperatures $(\mathrm{TXx} / \mathrm{TNx})$, summer days (SU25), tropical nights (TR20), the occurrence of warm days/nights (TX90p/TN90p), and the warm spell duration

Table 3 Indices for daily climate extremes based on ETCCDMI

\begin{tabular}{|c|c|c|}
\hline Extreme & ID & Definition \\
\hline \multirow[t]{7}{*}{ Warm $\left(\mathrm{T}_{\text {warm }}\right)$} & SU25 & Number of days with $\mathrm{TX}>25^{\circ} \mathrm{C}$ \\
\hline & TR20 & Number of days with $\mathrm{TN}>20^{\circ} \mathrm{C}$ \\
\hline & $\mathrm{TXx}$ & Maximum value of TX \\
\hline & $\mathrm{TNx}$ & Maximum value of $\mathrm{TN}$ \\
\hline & TN90p & Number of days with $\mathrm{TN}>90$ th percentile \\
\hline & TX90p & Number of days with $\mathrm{TX}>90$ th percentile \\
\hline & WSDI & $\begin{array}{l}\text { Number of days with at least } 6 \text { consecutive } \\
\text { days with } \mathrm{TX}>90 \text { th percentile }\end{array}$ \\
\hline \multirow[t]{7}{*}{ Cold $\left(\mathrm{T}_{\text {cold }}\right)$} & FD0 & Number of days with $\mathrm{TN}<0^{\circ} \mathrm{C}$ \\
\hline & ID0 & Number of days with $\mathrm{TX}>0^{\circ} \mathrm{C}$ \\
\hline & TXn & Minimum value of TX \\
\hline & TNn & Minimum value of $\mathrm{TN}$ \\
\hline & TN10p & Number of days with $\mathrm{TN}<10$ th percentile \\
\hline & TX10p & Number of days with $\mathrm{TX}<10$ th percentile \\
\hline & CSDI & $\begin{array}{l}\text { Number of days with at least } 6 \text { consecutive } \\
\text { days with } \mathrm{TN}<10 \text { th percentile }\end{array}$ \\
\hline \multirow[t]{9}{*}{ Wet $\left(\mathrm{P}_{\text {wet }}\right)$} & RX1d & The largest 1 day rainfall total \\
\hline & $\mathrm{RX} 5 \mathrm{~d}$ & The largest 5 day rainfall total \\
\hline & SDII & Simple daily intensity index \\
\hline & $\mathrm{R} 10$ & Number of days with PRCP $>10 \mathrm{~mm}^{\text {day }}{ }^{-1}$ \\
\hline & $\mathrm{R} 20$ & Number of days with PRCP $>20 \mathrm{~mm}^{\text {day }}{ }^{-1}$ \\
\hline & $\mathrm{R} 50$ & Number of days with PRCP $>50 \mathrm{~mm}^{\text {day }}{ }^{-1}$ \\
\hline & R95p & Total amount of $\mathrm{PRCP}>95$ th percentile \\
\hline & R99p & Total amount of $\mathrm{PRCP}>99$ th percentile \\
\hline & PRCPTOT & Total amount of PRCP $>1 \mathrm{~mm}^{\text {day }}{ }^{-1}$ \\
\hline Dry $\left(P_{\text {dry }}\right)$ & CDD & $\begin{array}{l}\text { Maximum number of consecutive dry days } \\
\text { with } \mathrm{PRCP}<1 \mathrm{~mm}^{-1} \text { day }^{-1}\end{array}$ \\
\hline
\end{tabular}


indicators (WSDI). The cold extreme group $\left(\mathrm{T}_{\text {cold }}\right)$ consists of seven single indices including the minimum of daily maximum/minimum temperatures $(\mathrm{TXn} / \mathrm{TNn})$, the occurrence of cold days/nights (TX10p/TN10p), frost days (FD0), ice days (ID0), and the cold spell duration indicator (CSDI). In the wet category $\left(\mathrm{P}_{\mathrm{wet}}\right), 10$ single indices were grouped including: the maximum 1-day/5-day precipitation amounts (RX1day/RX5day), the annual precipitation total (PRCPTOT), simple daily intensity index (SDII) that shows precipitation rate, the number of very wet days (R95p), extremely wet days (R99p), heavy precipitation days $\left(>10 \mathrm{~mm} \mathrm{day}^{-1}\right.$; R10), very heavy precipitation days $\left(>20 \mathrm{~mm}\right.$ day $^{-1}$; $\mathrm{R} 20)$, and extreme precipitation days ( $\left.>50 \mathrm{~mm} \mathrm{day}^{-1} ; \mathrm{R} 50\right)$. The category of dry extreme $\left(\mathrm{P}_{\mathrm{dry}}\right)$ is represented by only one index: the consecutive dry days (CDD).

All indices above were calculated at each of the 750 meteorological stations. The station values were then converted into gridded values by averaging over the stations within a rectangular area of $5^{\circ} \times 5^{\circ}$ centered at the grid point. After gridding all single indices, the individual indices were divided by the spatial and temporal means of the corresponding variables, because taking an average of all indices in their original values can exaggerate the impact of certain indices due to their different units and magnitudes. This standardization by the spatiotemporal mean also allows the resultant gridded indices to represent the relative strength of the extreme in a region at a given day compared to other regions and/or other days. That is, a grid point value exceeding 1 means that the type of extreme event gridded is more frequent (or stronger) at the grid point than the climatological value over the entire analysis domain (i.e., East Asia), implying that the grid point is more vulnerable to the extreme.

After the individual indices were gridded, they were combined in the groups detailed above, with the seven warm indices grouped as index $\mathrm{T}_{\text {warm }}$, seven cold indices grouped as index $\mathrm{T}_{\text {cold }}$, nine wet indices grouped as index $\mathrm{P}_{\text {wet }}$, and the single dry extreme index noted as index $\mathrm{P}_{\mathrm{dry}}$. These group index grids visually show the change in the vulnerability of geographic residential regions to the corresponding extremes due to global warming. This visualization could be of significant use to policy makers, who can now easily compare the vulnerability of their region at present to the past vulnerability in the whole of East Asia, and can plan accordingly.

\section{Extreme vulnerability in the historical archive}

To examine the historical variations in the vulnerability to extreme weather, we have investigated the climatology for the entire period (i.e., 1960s-2000s) and the anomalies of our four new group indices for each decade. The value of $\mathrm{T}_{\text {warm }}$ varies from 0.2 to 1.8 with the maximum value in the southern China coastal region (Fig. 1a). In the zonal band along $30^{\circ} \mathrm{N}$ and $40^{\circ} \mathrm{N}, \mathrm{T}_{\text {warm }}$ is generally larger in the eastern region with maxima over eastern China, Korea, and Japan, perhaps caused by the influence of the subtropical North Pacific high that covers the area during summer. Anomalies for each decade (Fig. 1b-f) show robust negative values in most of the region until the 1980s, and then they become positive in the 1990 s and 2000 s with a $95 \%$ confidence level (see gray dots). This pattern clearly indicates that warm temperature extremes represented by $\mathrm{T}_{\text {warm }}$ have been increasing during recent decades. In particular, as shown in the area marked by a rectangle in Fig. 1f, the increase in $\mathrm{T}_{\text {warm }}$ is especially large over northern China and Korea with the values ranging from 0.05 to 0.3 in the $2000 \mathrm{~s}, 25 \%$ higher than the climatological averages for the region; compared to the $1960 \mathrm{~s}$, the increment in this area is $82 \%$ higher than the climatological average for the region. 
(a) Climatology

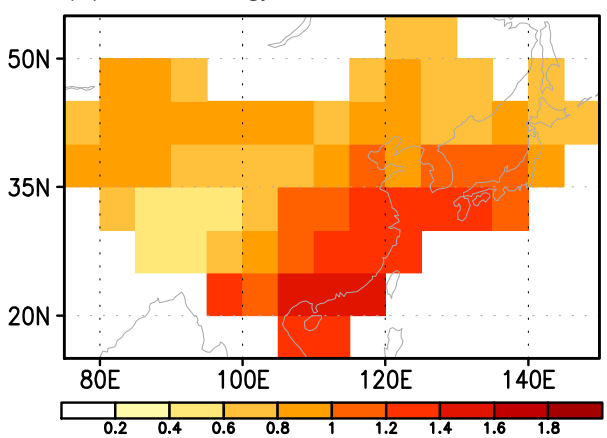

(c) $1970 \mathrm{~s}$

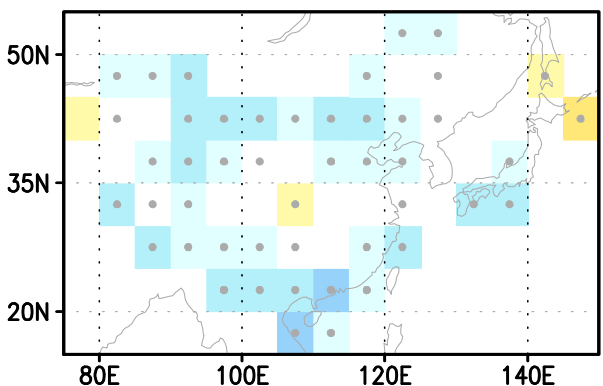

(e) $1990 \mathrm{~s}$

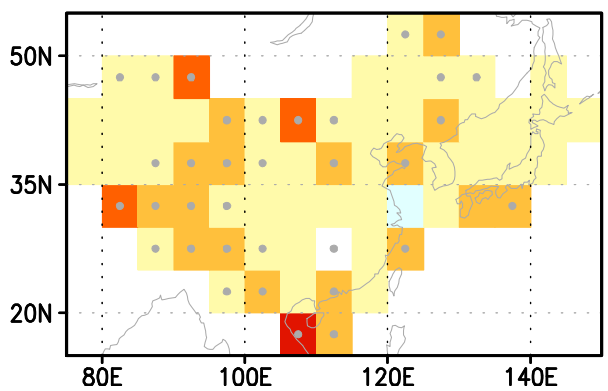

(b) $1960 \mathrm{~s}$

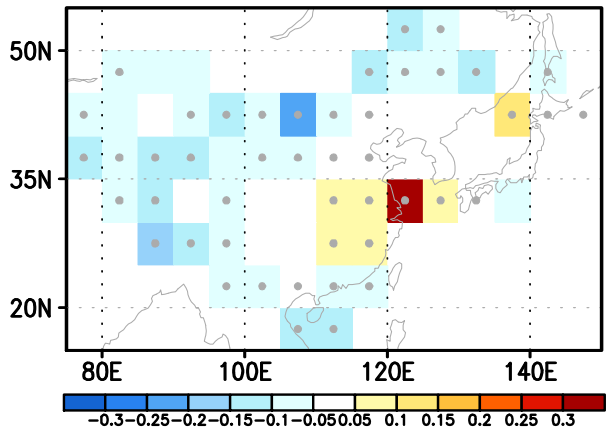

(d) 1980

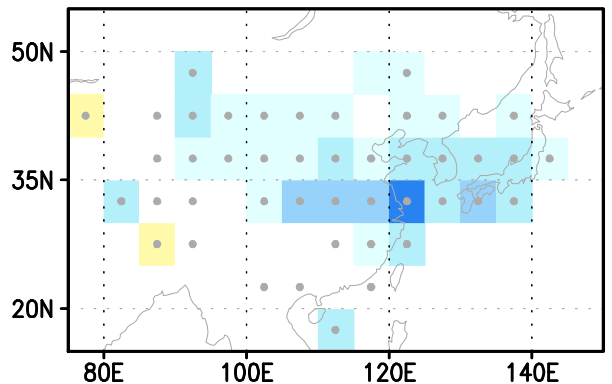

(f) $2000 \mathrm{~s}$

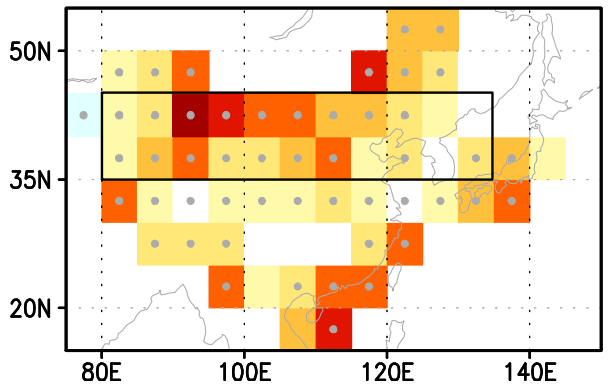

Fig. 1 Climatology (a) and anomalies of warm temperature extremes $\left(\mathrm{T}_{\text {warm }}\right)$ for the 1960s (b), 1970s (c), 1980s (d), 1990s (e), and 2000s (f). Regions significant at the $95 \%$ level are indicated by gray dots

Figure 2 shows both the mean and decadal anomalies of group index $\mathrm{T}_{\text {cold, }}$, which is characterized by larger values in the northern inland region and smaller values in the southern regions, especially along the coastline (Fig. 2a). In the decadal anomalies, positive anomalies are largely distributed in the inland region for the 1960s (Fig. 2b), then become weak and scattered in the 1970s and the 1980s (Fig. 2c and d). In the recent two decades of the 1990s and the 2000s, negative anomalies are dominant (Fig. 2e and f). This pattern clearly indicates that the cold extremes represented by $\mathrm{T}_{\text {cold }}$ have been decreasing over East Asia, particularly over the northern regions marked by a rectangle in Fig. 2f. This decreasing trend of $\mathrm{T}_{\text {cold }}$ seems to correspond to the increase of $\mathrm{T}_{\text {warm }}$ in the boxed region. Although warming due to urbanization over northeastern China would be one of the important factors contributing to the increase in $\mathrm{T}_{\text {warm }}$ and decrease in $\mathrm{T}_{\text {cold }}$ (Ren et al. 
(a) Climatology

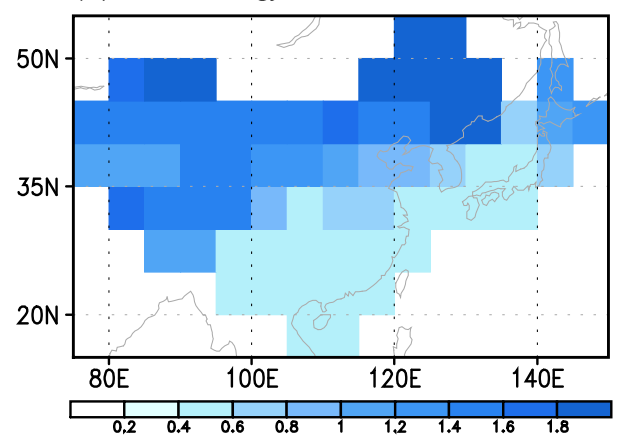

(c) $1970 \mathrm{~s}$

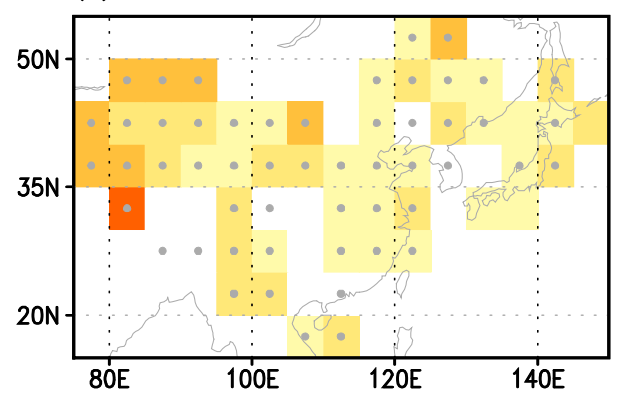

(e) $1990 \mathrm{~s}$

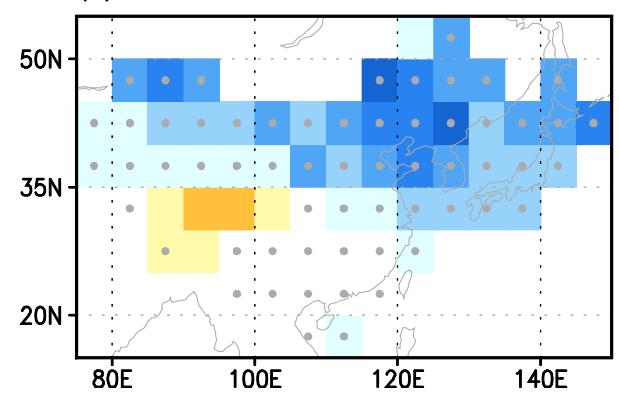

(b) $1960 \mathrm{~s}$

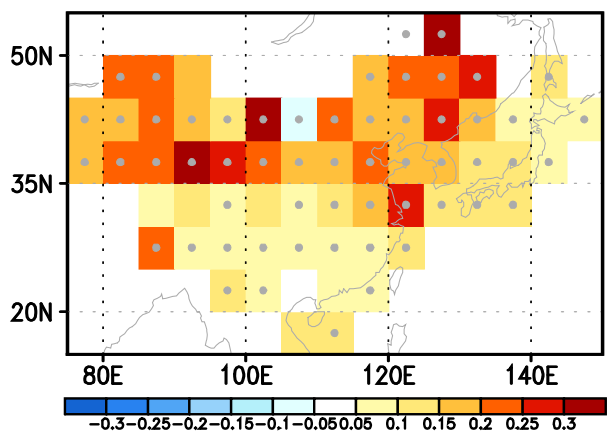

(d) $1980 \mathrm{~s}$

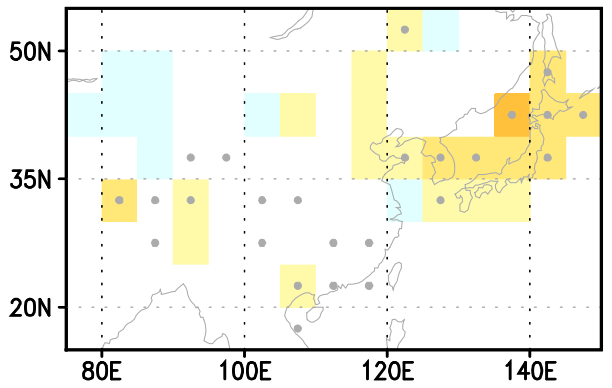

(f) $2000 \mathrm{~s}$

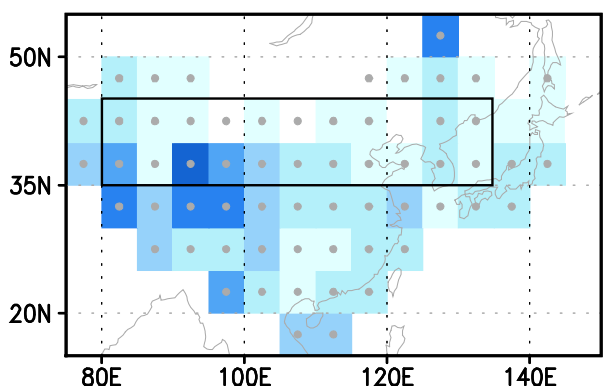

Fig. 2 Same as Fig. 1 except for cold temperature extremes $\left(\mathrm{T}_{\text {cold }}\right)$

2008), the significant changes are consistently found in the rural region in the western China. We believe this indicates that changes in vulnerabilities to warm/cold extremes during recent decades can be interpreted as signals related to global warming (Zhai and Pan 2003; Gong and Ho 2004; Alexander et al. 2006; Meehl et al. 2007).

Climatological vulnerability to wet extremes is generally large in the coastal regions in China, Korea, and Japan, which are strongly affected by the East Asian monsoon system and tropical storms (Fig. 3a). Unlike the two temperature extreme indices ( $\mathrm{T}_{\text {warm }}$ and $\left.\mathrm{T}_{\text {cold }}\right)$, $\mathrm{P}_{\text {wet }}$ anomalies are not spatially and/or temporally organized (Fig. 3b-f), which implies that wet extremes vary in a more complex manner spatially and temporally than do temperature extremes. Nevertheless, the increase in $\mathrm{P}_{\text {wet }}$ from the 1960s to 2000s in the vicinity of the Korean peninsula (the box area in Fig. 3f) is clearly defined in temporal variations of the index, increasing by about $50 \%$ during the period. This increase in precipitation extremes 
over Korea adds to a consensus of previous studies (e.g., Ho et al. 2003; Wang et al. 2006; Kim et al. 2006) which conclude that Korea has become more vulnerable to wet extremes in recent decades.

The climatology and anomalies of $\mathrm{P}_{\mathrm{dry}}$ are plotted in Fig. 4. Note that, unlike the other three indices, $\mathrm{P}_{\text {dry }}$ is composed of a single index, CDD. Climatologically, the largest value appears over the desert in northern China, which is nearly three times as large as values over the eastern region including eastern China, Korea, and Japan that are strongly affected by monsoon rainfall (Fig. 4a). Dry extremes are influenced mostly by large-scale circulations rather than regional convections, so the anomalies of $\mathrm{P}_{\text {dry }}$ show more coherent spatial patterns than $\mathrm{P}_{\text {wet }}$ (Fig. 4b-f). In northern inland China, which is affected by large variations in temperature extremes (the box area in Fig. 4f), the vulnerability to dry

\section{(a) Climatology}

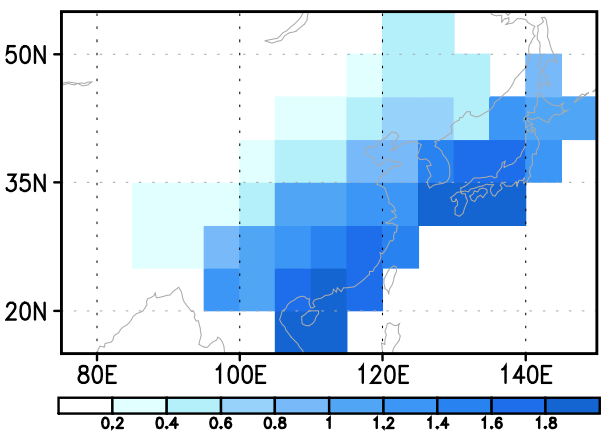

(c) $1970 \mathrm{~s}$

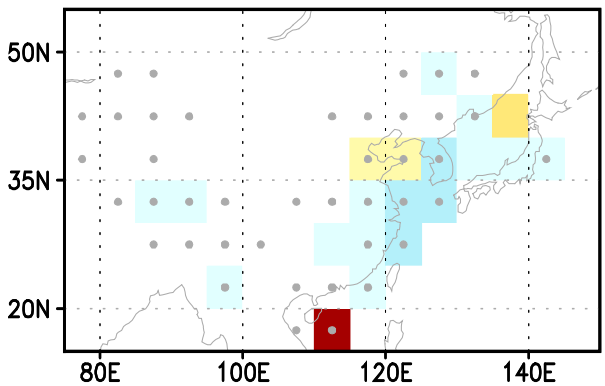

(e) $1990 \mathrm{~s}$

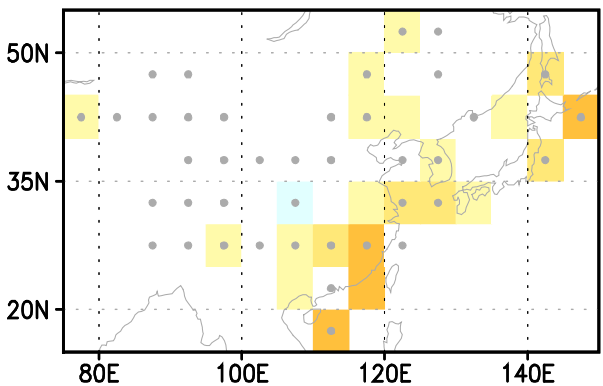

(b) $1960 \mathrm{~s}$

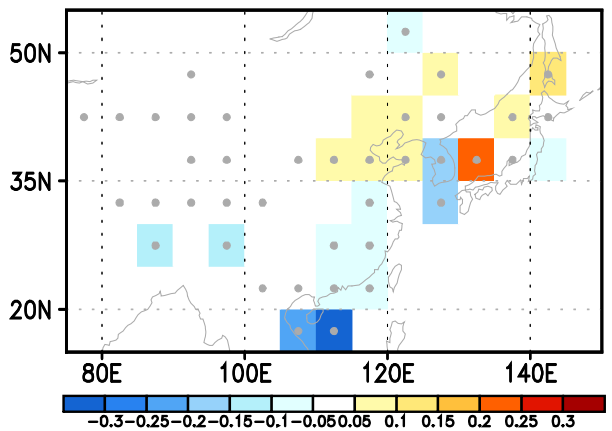

(d) $1980 \mathrm{~s}$

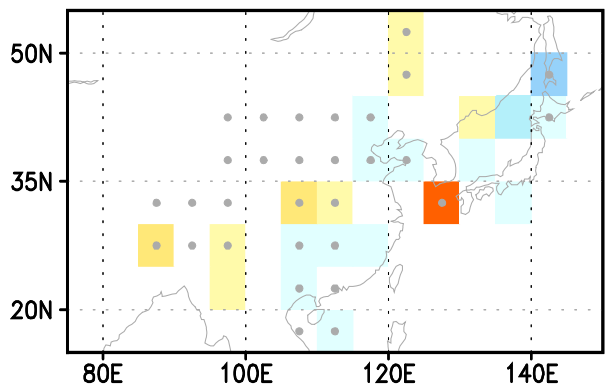

(f) $2000 \mathrm{~s}$

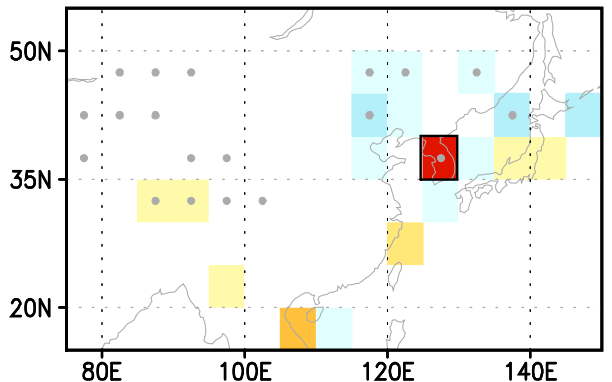

Fig. 3 Same as Fig. 1 except for wet precipitation extremes $\left(\mathrm{P}_{\text {wet }}\right)$ 
extremes intensified from the 1960 s to 2000 s, consistent with the documented recent desertification of northern China (Yang et al. 2007; Wang et al. 2008).

Having analyzed the spatial distributions and decadal variations of the four indices from the climatology and the anomalies of each index per decade, we were able to recognize the locations of the core variability region of each index. However, the anomalies cannot show how much the core variability regions are vulnerable to these extremes compared to other regions, because the anomalies are simply the departures from the climatological averages. To approach this problem, we examined the annual time series of the four group indices averaged over the core variability region for each index. We also investigated the time series of the original individual indices that were grouped into the new indices, to examine whether the signal of change is exaggerated by combining several similar indices.

(a) Climatology

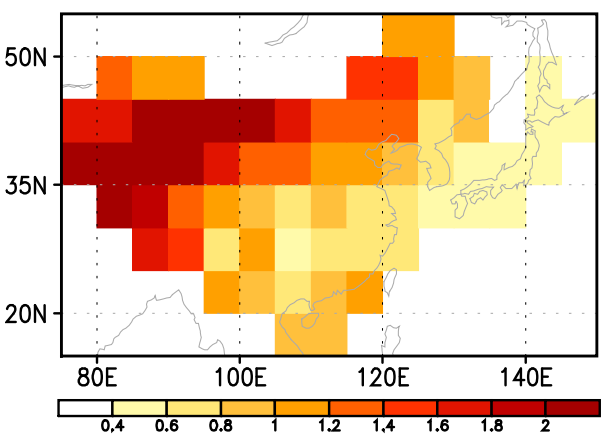

(c) $1970 \mathrm{~s}$

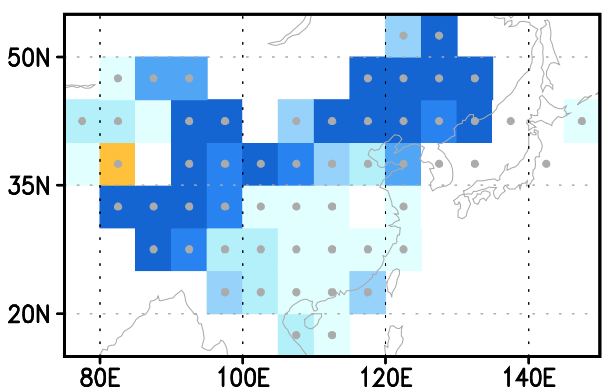

(e) $1990 \mathrm{~s}$

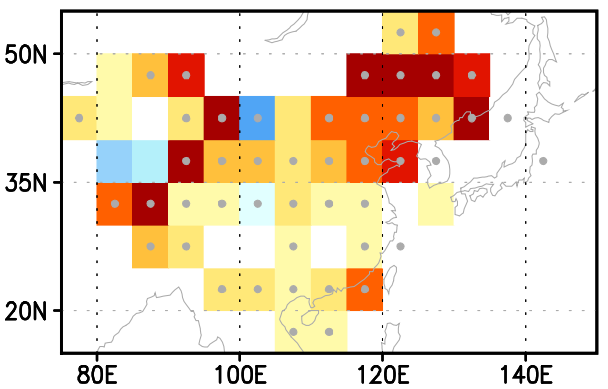

(b) $1960 \mathrm{~s}$

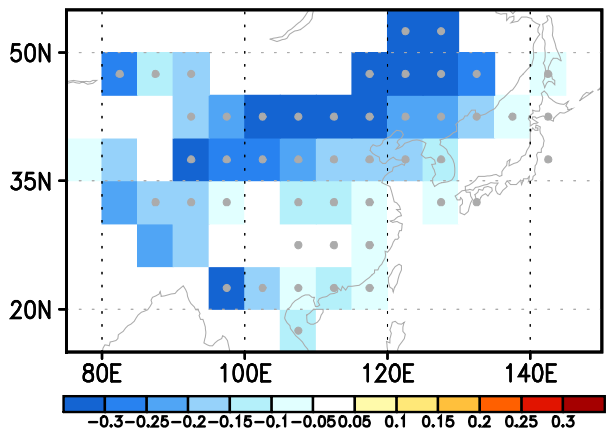

(d) $1980 \mathrm{~s}$

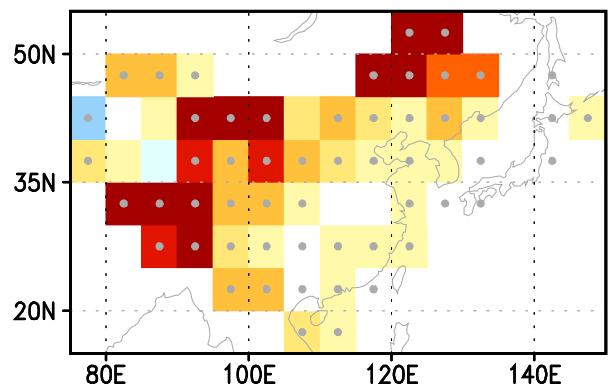

(f) $2000 \mathrm{~s}$

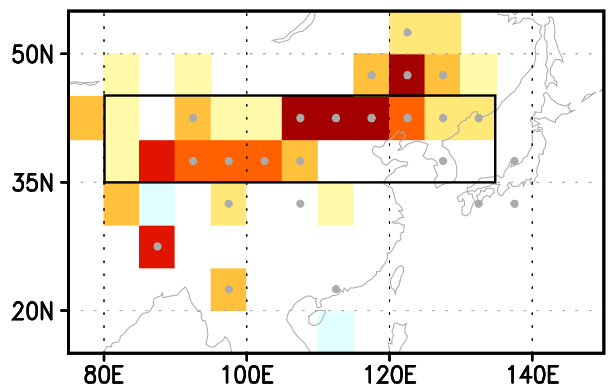

Fig. 4 Same as Fig. 1 except for dry precipitation extremes $\left(\mathrm{P}_{\text {dry }}\right)$ 
The black solid line in Fig. 5a shows the $T_{\text {warm }}$ time series averaged over the core variability region, a rectangular region of $80^{\circ} \mathrm{E}-150^{\circ} \mathrm{E}$ and $35^{\circ} \mathrm{N}-45^{\circ} \mathrm{N}$. $\mathrm{T}_{\text {warm }}$ values were about 0.8 in the 1960 s, exceeded 1 after the 1990 s, and since the 1990 s have continuously increased with a statistical significance of $95 \%$, implying that the impact of warm extremes in the region has become stronger as compared to the climatological mean for the entire

(a) T_warm (80E 135E, 35N 45N)
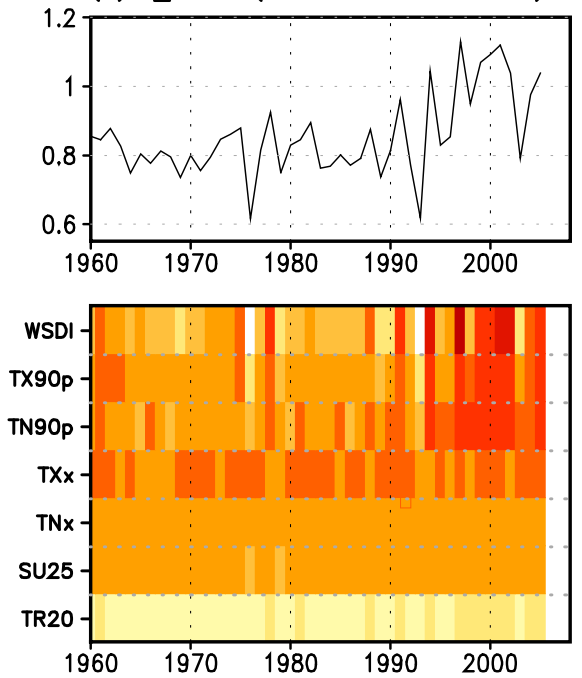

(c) P_wet (125E 130E, 35N 40N)
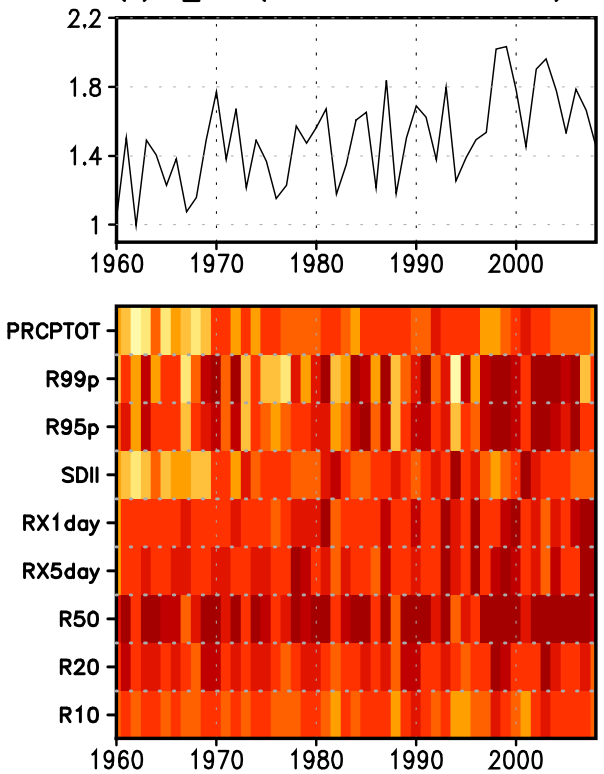

(b) T_cold (80E 135E, 35N 45N)
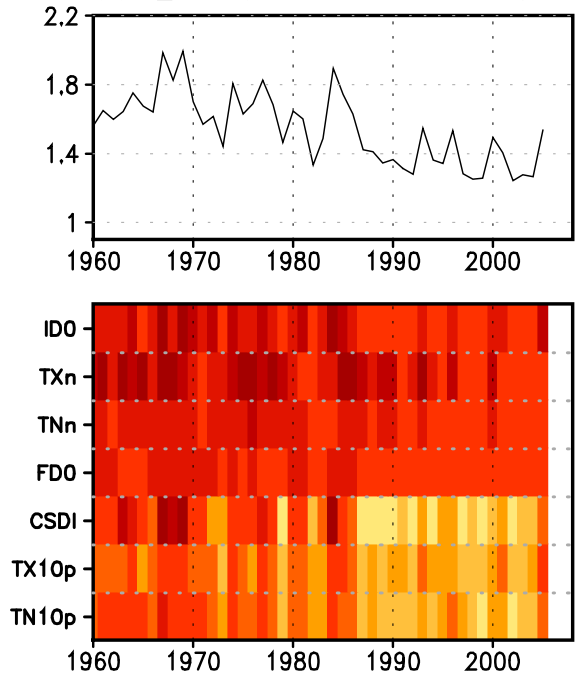

(d) P_dry (80E 135E, 35N 45N)

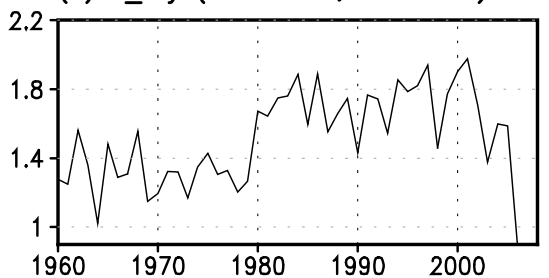

\begin{tabular}{|c|c|}
\hline ID & Indicotor name \\
\hline $\begin{array}{l}\text { WSDI/CSDI } \\
\text { TX90p/10p } \\
\text { TN90p/10p } \\
\text { TNx/TNn } \\
\text { TXX/TXn } \\
\text { TR20 } \\
\text { SU25 } \\
\text { IDO } \\
\text { FDO } \\
\text { PRCPTOT } \\
\text { R99p/R95p } \\
\text { R50/20/10 } \\
\text { SDII } \\
\text { RX1/5doy } \\
\text { CDD }\end{array}$ & $\begin{array}{l}\text { Warm/Cold spell duration index } \\
\text { Number of Warm/Cold day } \\
\text { Number of Warm/Cold night } \\
\text { Maximum/Minimum of Tmin } \\
\text { Maximum/Minimum of Tmax } \\
\text { Tropical night } \\
\text { Summer day } \\
\text { Ice day } \\
\text { Frost day } \\
\text { Annual total wet day PRCP } \\
\text { Extremely/very wet day } \\
\text { Number of PRCP over } 50 / 20 / 10 \mathrm{~mm} \\
\text { Simple daily intensity index } \\
\text { Max } 1 / 5 \text { day PRCP } \\
\text { Consecutive dry day }\end{array}$ \\
\hline
\end{tabular}

Fig. 5 Time series of domain averaged indices and individual components for $T_{\text {warm }}(\mathbf{a}), \mathrm{T}_{\text {cold }}(\mathbf{b}), \mathrm{P}_{\text {wet }}(\mathbf{c})$, and $\mathrm{P}_{\mathrm{dry}}(\mathbf{d})$. The lower part of the panel (d) shows what the individual indices used in the construction of the integrated index indicate and a color bar for the time series of the individual indices in (a)-(c) 
East Asia region. As seen in the lower panel of the figure, this change is consistently found in the time series of the individual indices used in the construction of the integrated index. All indices show the increase in the corresponding warm extremes in the region, especially after the 1990s. In particular, the frequency indices (i.e., WSDI, TX90p, TN90p) have increased more than the intensity indices (i.e., TXx, TNx). Figure $5 \mathrm{~b}$ presents the time series of $\mathrm{T}_{\text {cold }}$ and the individual components averaged over the same area with $\mathrm{T}_{\text {warm }}$. Even though $\mathrm{T}_{\text {cold }}$ has gradually decreased until the $2000 \mathrm{~s}$ with a statistical significance of $95 \%$, the values remain greater than unity. This implies that $T_{\text {cold }}$ responds more gradually to the global warming than $\mathrm{T}_{\text {warm }}$ does. For each index, an obvious decreasing trend in found in CSDI, TX10p, and TN10p.

Figures 5c and $d$ represent the averaged time series of $\mathrm{P}_{\text {wet }}$ and $\mathrm{P}_{\mathrm{dry}}$, respectively. Since $\mathrm{P}_{\text {wet }}$ is significant only in one grid that includes Korea, the index is averaged only for the region $125^{\circ} \mathrm{E}-130^{\circ} \mathrm{E}$ and $35^{\circ} \mathrm{N}-45^{\circ} \mathrm{N}$. From 1961 to $2008, \mathrm{P}_{\text {wet }}$ has steadily increased by $50 \%$, with more rapid increases after the 1990s. All the individual indices are greater than 1 , indicating that Korea is strongly affected by precipitation extremes in general. In particular, the heavy extremes such as R99p and R50 show much greater values than the moderate extremes such as R95p and R10 over the region. The time series in Fig. 5d shows that $P_{\text {dry }}$ values averaged over the same area as the temperature indices, including selected regions of inland China that are climatologically dry, have increased in recent decades. In particular, the time series of $\mathrm{P}_{\text {dry }}$ shows a large shift after the late 1970 s with a statistical significance of $95 \%$, which means that the number of consecutive zero precipitation days has increased after the late 1970s (Ho et al. 2005).

\section{Future extreme vulnerability projected in the model simulations}

In order to assess the impact of global climate change on the weather extremes in East Asia, the new grouped indices have been calculated from the outputs of CCSM3 simulations (Section 2.1). Model-projections of changes in extremes suffer from large uncertainties, in particular, on the regional scale; however, at present, a climate model approach appears to be the best way to estimate the tendency of the changes in extremes.

We analyzed the output of a 20C3M scenario run covering 1900 to 1999 to evaluate the CGCM under the present-day climate condition. Figures 6 and 7 show the climatology and anomalies of $\mathrm{T}_{\text {warm }}$ and $\mathrm{T}_{\text {cold }}$, respectively; the spatiotemporal variations of model output are shown in 20-year increments from 1900 to 1999. Compared to the observed climatology of $\mathrm{T}_{\text {warm}}$, the value from the $20 \mathrm{C} 3 \mathrm{M}$ run is shown to be greater in general, especially in southern China and Japan (Fig. 6a). The core of the variability occurs over these regions in the model simulation, though the observations locate the variability core in the inland area of China; this discrepancy shows the limitations of the CCSM3. As a whole, the pattern of enhancement of $\mathrm{T}_{\text {warm }}$ over East Asia in recent years is nearly the same as that of the observations (Fig. 6b-f). In the case of $\mathrm{T}_{\text {cold }}$ (Fig. 7), except for the overestimation in the southern region, the climatological values are similar to observed values in distribution and range, and the core of variability is also shown in the northern part of China, although it tends to be shifted slightly to the east. The pattern of variation is also consistent with that of the observations, showing that using the model results for projection of $T_{\text {warm }}$ and $T_{\text {cold }}$ is reasonable despite some uncertainty in projection of detailed features.

Figures 8 and 9 present the results of $\mathrm{P}_{\text {wet }}$ and $\mathrm{P}_{\text {dry }}$, respectively. It is well known that the simulation of precipitation is one of the most difficult problems in GCM study, especially on the local and quantitative approaches, so it is not surprising that though the model 
(a) Climatology

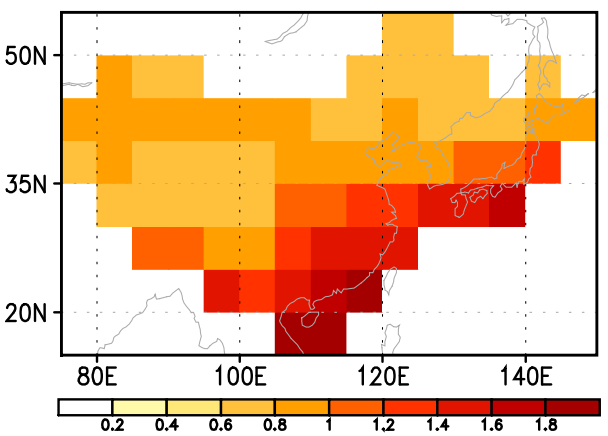

(c) 1920-1939

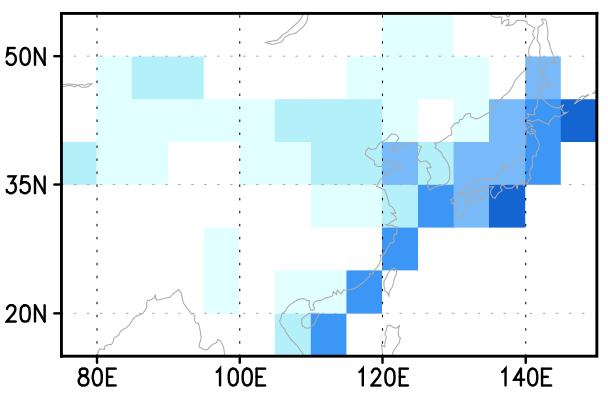

(e) 1960-1979

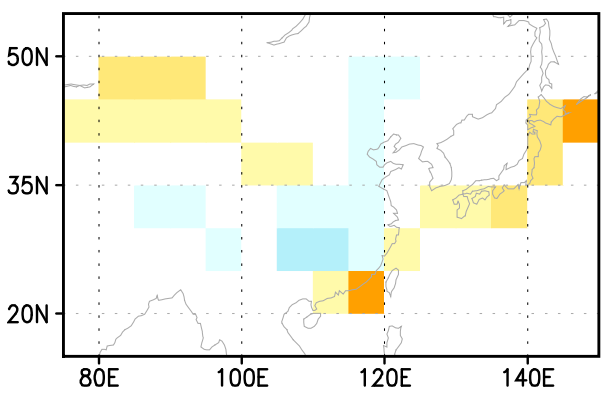

(b) $1900-1919$

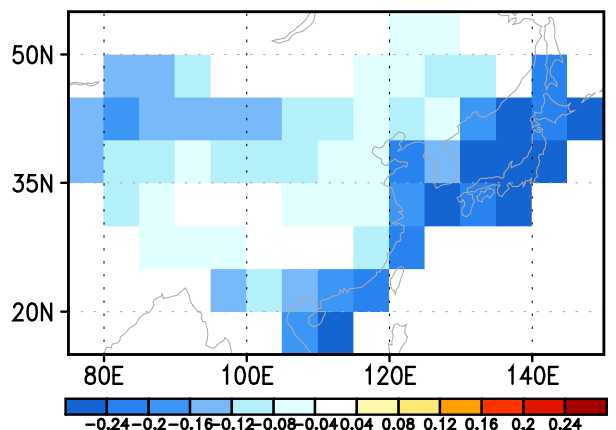

(d) 1940-1959

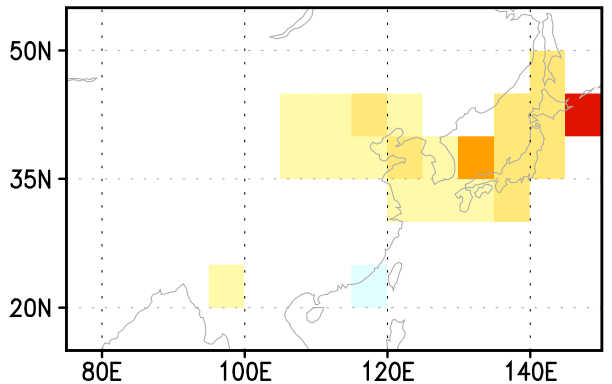

(f) $1980-1999$

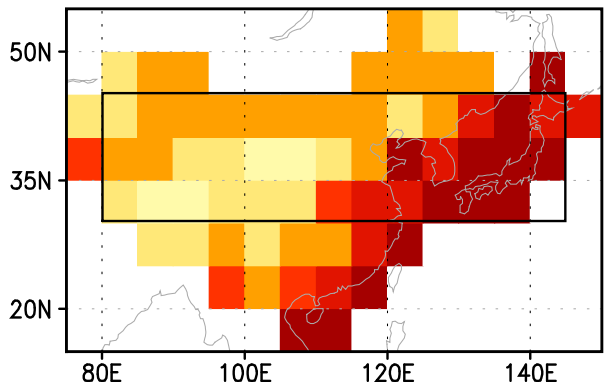

Fig. 6 Climatology (a) and anomalies of $\mathrm{T}_{\text {warm }}$ from 20C3M output for 1900-1919 (b), 1920-1939 (c), 1940-1959 (d), 1960-1979 (e), and 1980-1999 (f)

climatology of $\mathrm{P}_{\text {wet }}$ shows similar features as the observations over the southern coastal region it overestimates over the inland China region (Fig. 8a). In the anomalies (Fig. 8b-f), the spatial distribution is scattered, similar to the observations. Considering only the changes from 1960 to $1999, \mathrm{P}_{\text {wet }}$ seems to increase in the vicinity of Korean Peninsula, however, the significant increase over Korea found in the observations does not appear in the model data. Compared to the observations, $P_{\text {dry }}$ is underestimated in the $20 \mathrm{C} 3 \mathrm{M}$ simulation, and the high observed values over the northwestern part of the region cannot be found in the model shown in Fig. 9a. Particularly, the model does not show the signal of desertification over China in the anomalies of $P_{\text {dry }}$ (Fig. 9b-f). The spatial distribution of anomalies in the model shows a dispersive pattern unlike the homogeneous pattern in the analysis of the observation. Given these results, we now know that obtaining reliable 
(a) Climatology

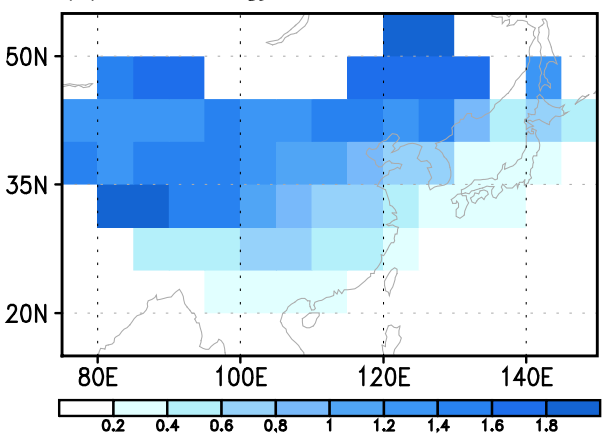

(c) $1920-1939$

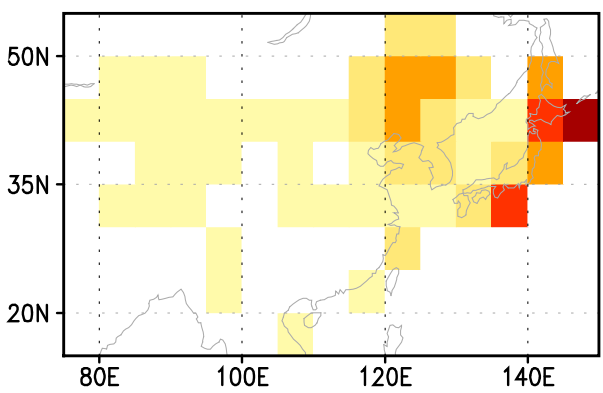

(e) $1960-1979$

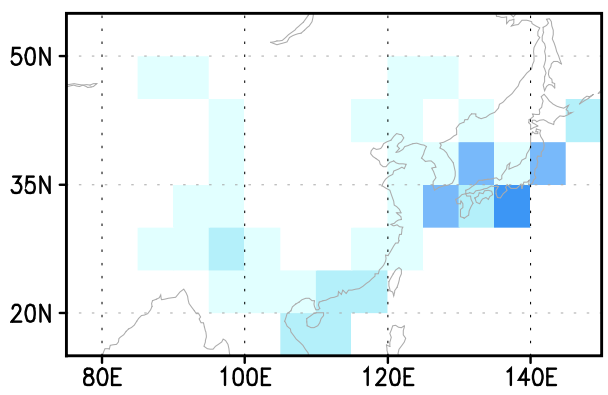

(b) $1900-1919$

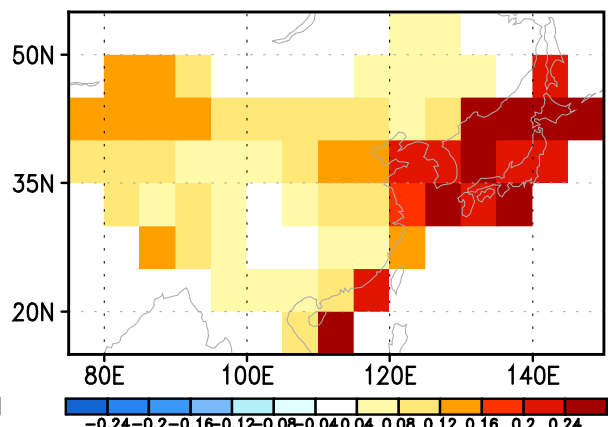

(d) $1940-1959$

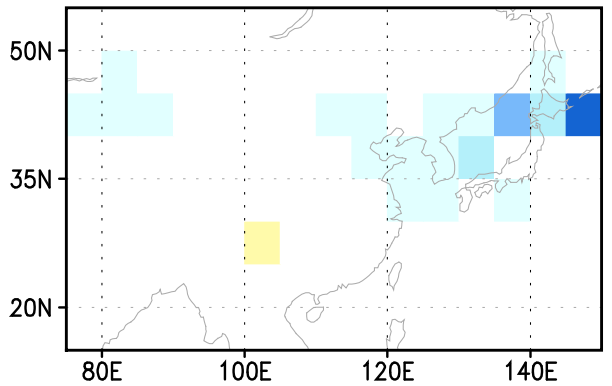

(f) $1980-1999$

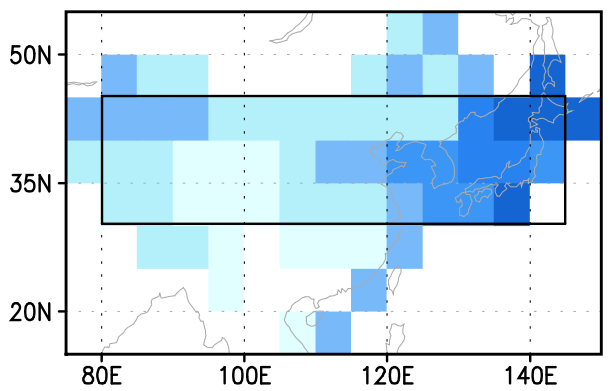

Fig. 7 Same as Fig. 6 except for $\mathrm{T}_{\text {cold }}$

precipitation estimates from GCM simulation is difficult not only for mean climate modeling but also for modeling extremes, and we have excluded the modeling results of precipitation extremes from further consideration..

The primary goal of our efforts to project the changes in extremes is to estimate the future climate state. For this work, we used three SRES emissions scenarios including A2, $\mathrm{A} 1 \mathrm{~B}$, and B1, for simulating the 21 st-century climate. To easily compare the changes in the 21 st century to those in the 20 th century, we used the same value as the $20 \mathrm{C} 3 \mathrm{M}$ (i.e., the averaged value over whole region during 1900-1999 in 20C3M) for the normalization of individual indices. Although the degree of changes varies between the three scenarios, the spatial patterns are similar among them (figure not shown). In further discussion, we will only explain the spatial variation of extreme vulnerability in the climate with the A2 scenario, in which the highest rate of carbon emission is assumed. 
(a) Climatology

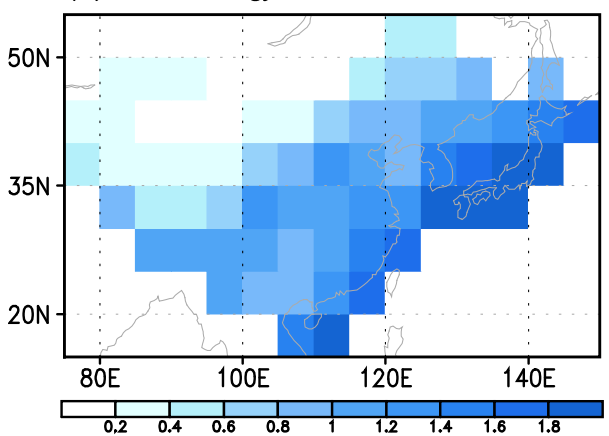

(c) $1920-1939$

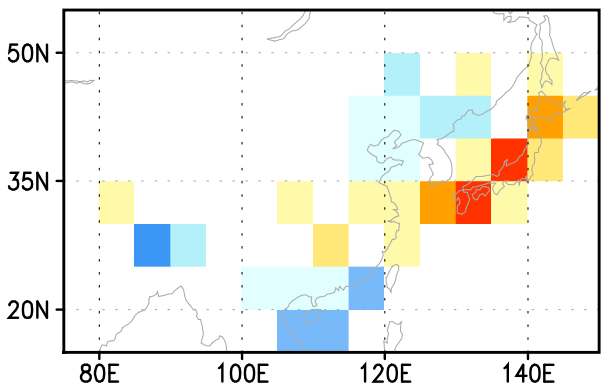

(e) $1960-1979$

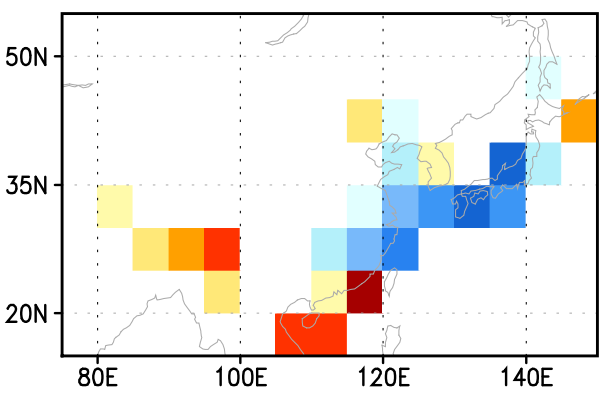

(b) $1900-1919$

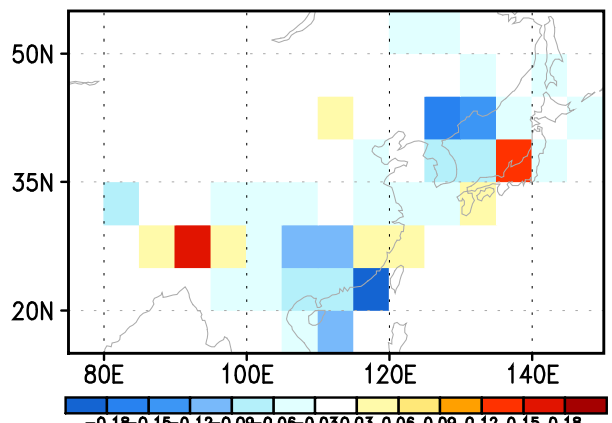

(d) $1940-1959$

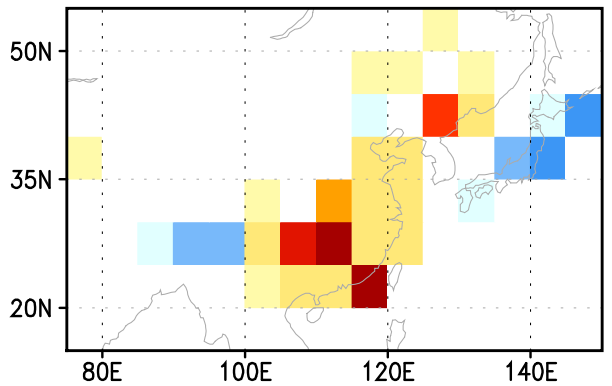

(f) $1980-1999$

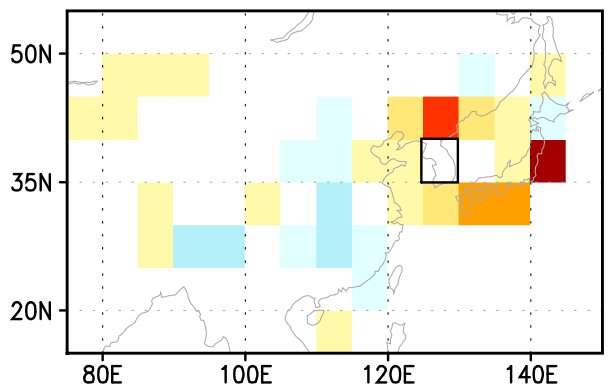

Fig. 8 Same as Fig. 6 except for $\mathrm{P}_{\text {wet }}$

Figures $10 \mathrm{a}-\mathrm{f}$ show the mean of $\mathrm{T}_{\text {warm }}$ during the last 20 years in the $20 \mathrm{C} 3 \mathrm{M}$ simulation and the deviation of the projected $\mathrm{T}_{\text {warm }}$ into the $21 \mathrm{st}$ century from the 20 -year mean, respectively. As expected, the amplitudes of changes in the projected index are very large; for instance, the mean of $\mathrm{T}_{\text {warm }}$ during the last 20 years of 20th century has a range between 0 and 2, but its increment during the 100 years of the 21 st century is more than 1.8 in the region of maximum anomaly. Figure 11 shows the same calculations for $\mathrm{T}_{\text {cold; }}$; although the amplitude of changes in $T_{\text {cold }}$ is not as much as that in $T_{\text {warm }}$, the decreasing trend is apparent over the whole region.

It is noteworthy that the negative trend in $\mathrm{T}_{\text {cold }}$ exists even in the southernmost region where the value in the last 20 years of $20 \mathrm{C} 3 \mathrm{M}$ is nearly zero. This means that $\mathrm{T}_{\text {cold }}$ over the region during the 21 st century is the negative value itself, which could be induced by the fact that $T_{\text {cold }}$ includes the index using the absolute value of daily minimum temperature, 


\section{(a) Climatology}

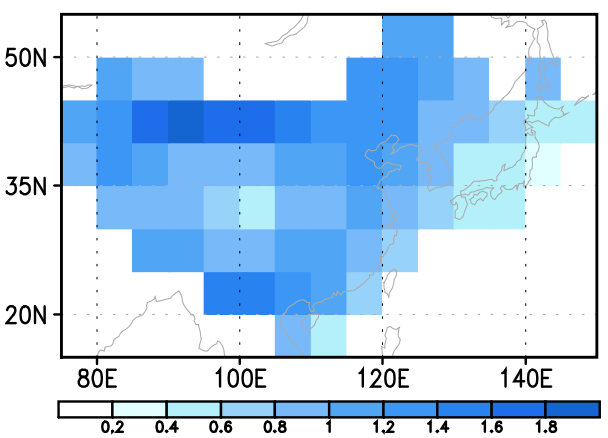

(c) $1920-1939$

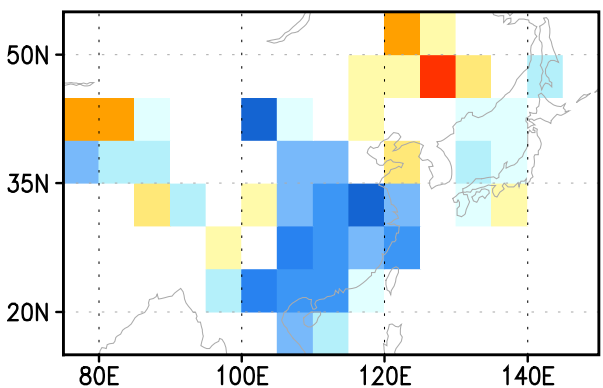

(e) $1960-1979$

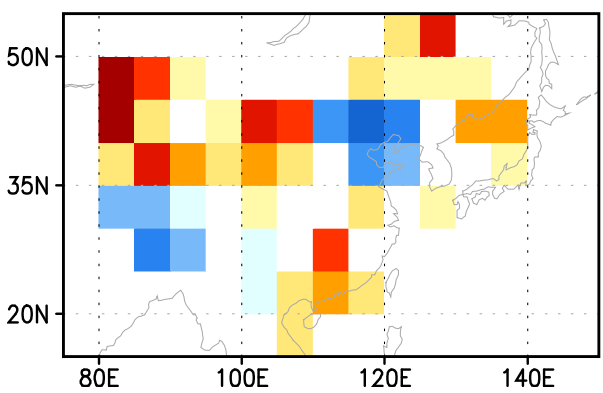

(b) $1900-1919$

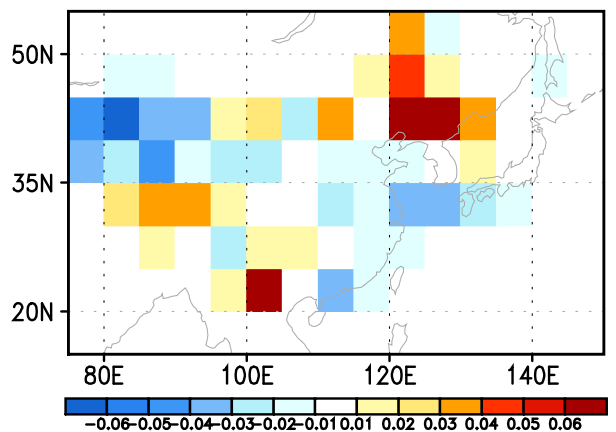

(d) $1940-1959$

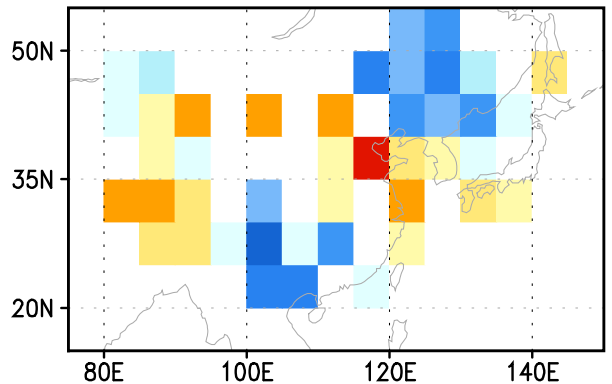

(f) $1980-1999$

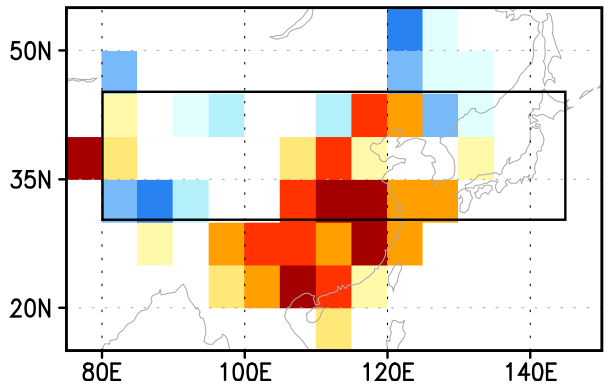

Fig. 9 Same as Fig. 6 except for $P_{\text {dry }}$

TNn. In other words, when the value used for normalization (i.e., averaged value over the temporal and spatial domain) is negative and the original TNn is positive in a certain grid, the normalized TNn can have a negative value in the grid. Then, if this normalized TNn contributes more to $T_{\text {cold }}$ than the other six individual indices, $T_{\text {cold }}$ may have a negative value. We could not find the negative value of $\mathrm{T}_{\text {cold }}$ in the observations or $20 \mathrm{C} 3 \mathrm{M}$ simulation, suggesting that the influence of $\mathrm{TNn}$ may not be very large, but, in the A2 scenario for the $21 \mathrm{st}$ century, TNn over the southern region rapidly increases to a large positive value, while the value used for normalization shows a small negative value. In that interval, the influence of TNn is apparently sufficient to make $T_{\text {cold }}$ negative.

Following the analysis of the observed data, we examined the temporal variation of domain-average indices using model outputs. As noted in Figs. 6 and 7, the selected domain is confined to $80^{\circ} \mathrm{E}-145^{\circ} \mathrm{E}, 30^{\circ} \mathrm{N}-45^{\circ} \mathrm{N}$, which is an extensive region including a 
(a) $1980-1999$ (20C3M)

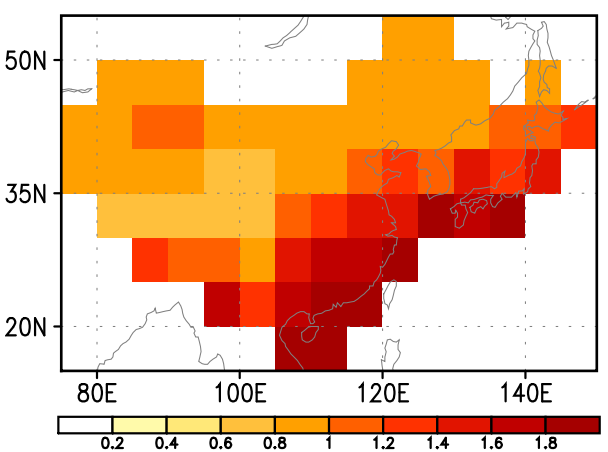

(c) $2020-2039$

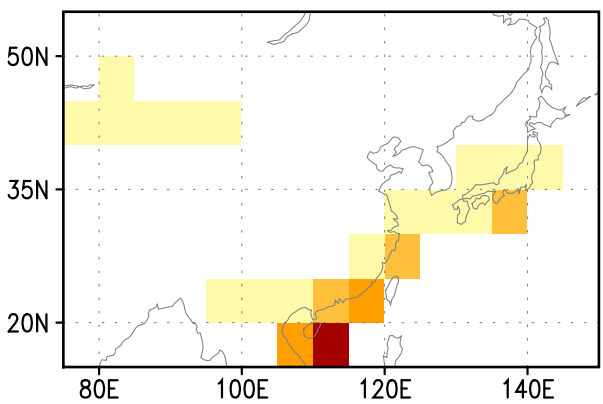

(e) 2060-2079

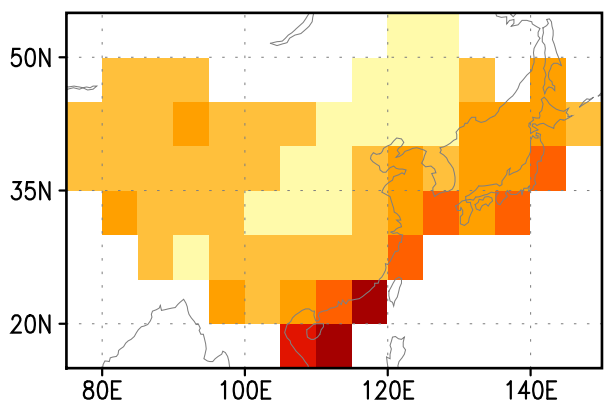

(b) $2000-2019$

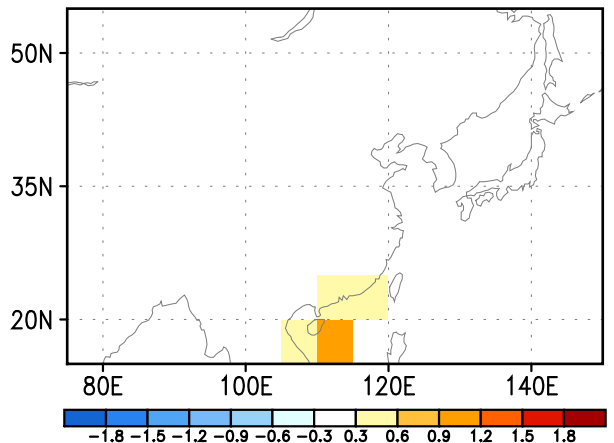

(d) 2040-2059

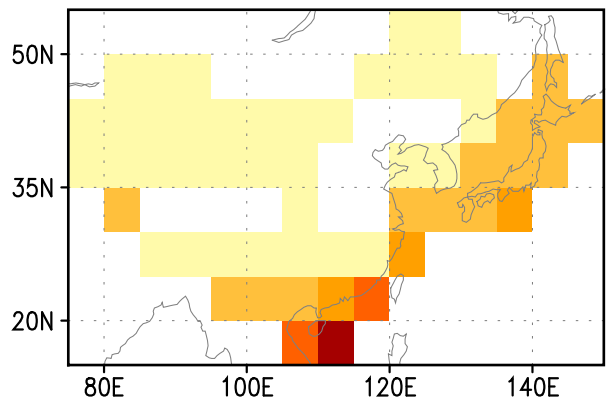

(f) $2080-2099$

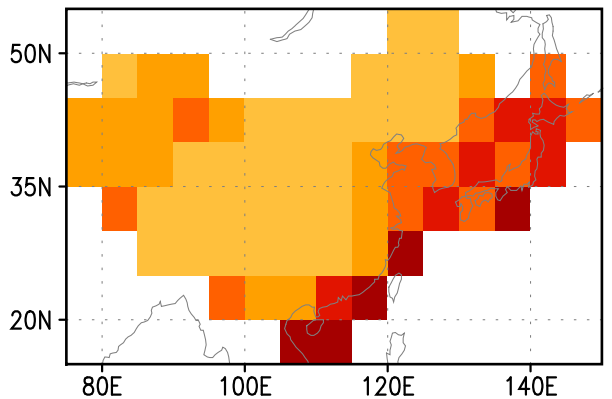

Fig. 10 Mean of $\mathrm{T}_{\text {warm }}$ during the last 20 years in the 20C3M simulation (a) and the deviation of the projected $\mathrm{T}_{\text {warm }}$ into the A2 simulation from the 20-year mean during 2000-2019 (b), 2020-2039 (c), 20402059 (d), 2060-2079 (e), and 2080-2099 (f)

large variability compared to that of the observation analysis. To compare the changes in the different climate conditions, we also analyzed B1 and A1B scenarios in which the lowest and intermediate rates of carbon emission are assumed, respectively. In Fig. 12, red, green, and blue solid lines display the changes in extreme vulnerability for A2, A1B, and B1 scenario simulations, respectively. To show historical change, the result of the $20 \mathrm{C} 3 \mathrm{M}$ scenarios is also plotted together as a black line. Consistent with the anomalies for each two-decade interval, $\mathrm{T}_{\text {warm }}$ shows increasing trends, and $\mathrm{T}_{\text {cold }}$ shows decreasing trends in all scenarios. The amplitude of changes is largest in A2 and lowest in B1 scenario, meaning that the further global warming progresses, the more $\mathrm{T}_{\text {warm }}$ and $\mathrm{T}_{\text {cold }}$ will change. 
(a) 1980-1999 (20C3M)

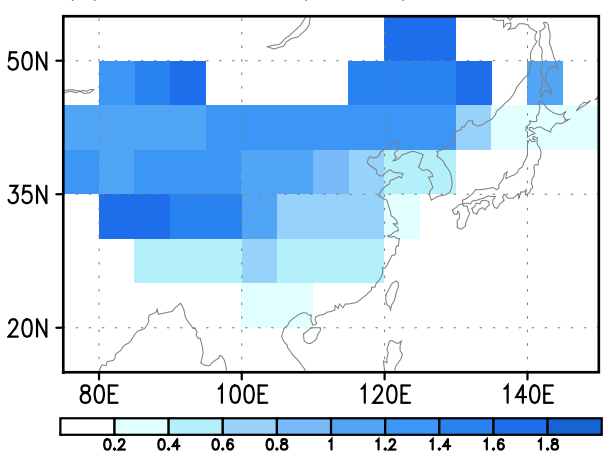

(c) 2020-2039

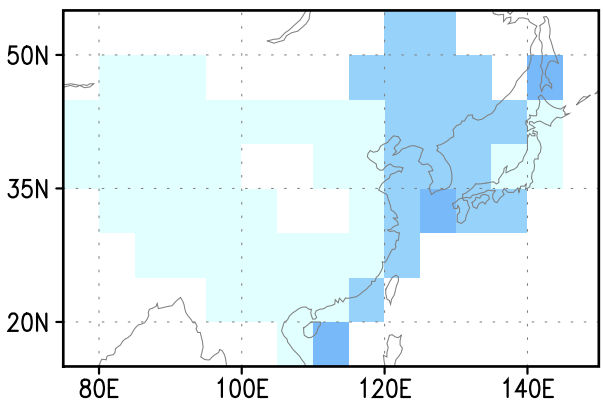

(e) 2060-2079

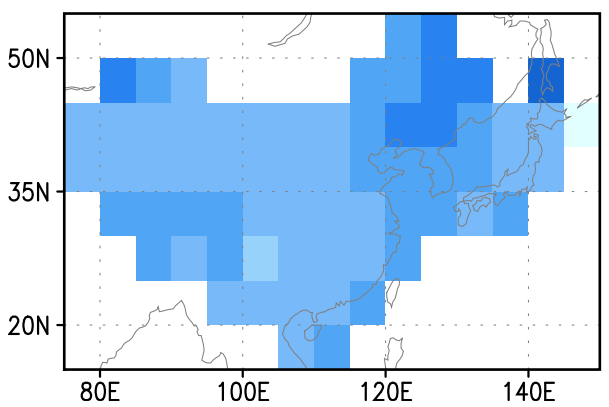

(b) $2000-2019$

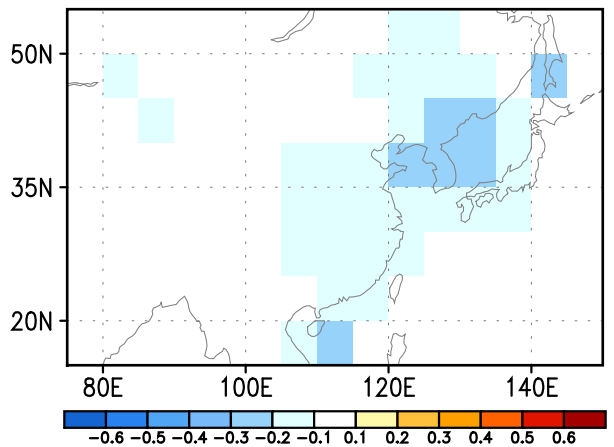

(d) 2040-2059

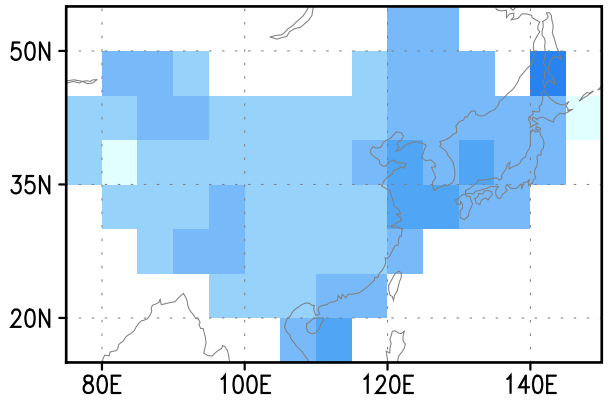

(f) 2080-2099

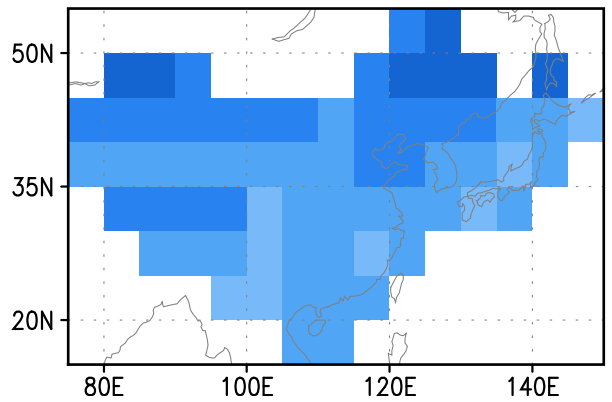

Fig. 11 Same as Fig. 10 except for $\mathrm{T}_{\text {cold }}$

Additional detailed assessment of changes in extreme vulnerability with various climate

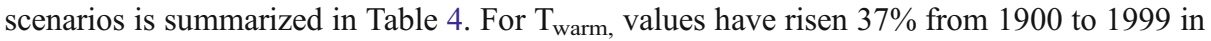
the $20 \mathrm{C} 3 \mathrm{M}$ simulation and risen $95 \%$ from 2000 to 2099 in the result of A2 scenario. Although the increment in the B1 scenario is small compared to the others, it is still $29 \%$. $\mathrm{T}_{\text {cold }}$ has dropped by $14 \%$ during 100 years of 20 th century observations, and by $70 \%$ during 100 years of 21 st century in the A2 scenario. In the future climate simulated by B1 scenario, the total decrement in $\mathrm{T}_{\text {cold }}$ is about $31 \%$, however, this change mainly occurs in the first 50 years of the 21 st century and the tendency of decline has disappeared after the 2040s.

To evaluate the projected changes in CCSM3 simulation, we additionally analyzed the output of six IPCC AR4 models for $\mathrm{T}_{\text {warm }}$ and $\mathrm{T}_{\text {cold. }}$. Figure 13 shows the mean of $\mathrm{T}_{\text {warm }}$ 
(a) Twarm (80E 145E, 30N 45N)

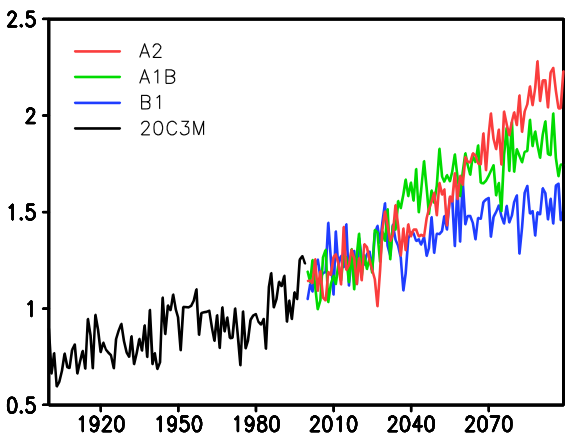

(b) Tcold (80E 145E, 30N 45N)

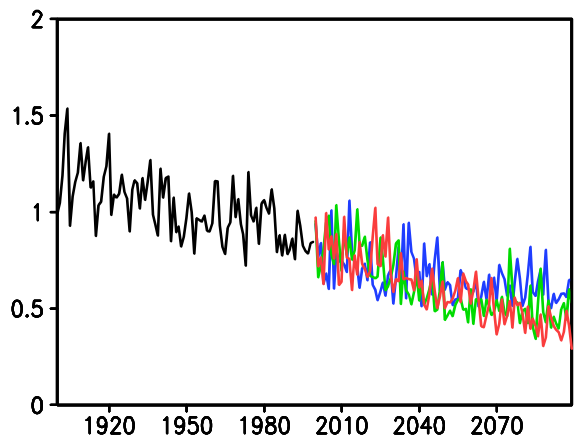

Fig. 12 Time series of domain averaged values for $T_{\text {warm }}$ indices (a) and $T_{\text {cold }}$ indices (b) from various model scenario run. Black, red, green, and blue solid lines indicate the results from 20C3M, A2, A1B, and B1 scenarios, respectively

Table 4 Changes $(\%)$ in $\mathrm{T}_{\text {warm }}$ and $\mathrm{T}_{\text {cold }}$ averaged over $80^{\circ} \mathrm{E}-145^{\circ} \mathrm{E}, 30^{\circ} \mathrm{N}-50^{\circ} \mathrm{N}$ for 20C3M (1900-1999), A2, A1B, and B1 (2000-2099) outputs

\begin{tabular}{lcc}
\hline & $\mathrm{T}_{\text {warm }}$ & $\mathrm{T}_{\text {cold }}$ \\
\hline $20 \mathrm{C} 3 \mathrm{M}(1900 \rightarrow 1999)$ & $+37 \%$ & $-14 \%$ \\
$\mathrm{~A} 2(2000 \rightarrow 2099)$ & $+95 \%$ & $-70 \%$ \\
$\mathrm{~A} 1 \mathrm{~B}(2000 \rightarrow 2099)$ & $+46 \%$ & $-45 \%$ \\
$\mathrm{~B} 1(2000 \rightarrow 2099)$ & $+29 \%$ & $-31 \%$ \\
\hline
\end{tabular}

and $\mathrm{T}_{\text {cold }}$ averaged over the region of $80^{\circ} \mathrm{E}-145^{\circ} \mathrm{E}, 30^{\circ} \mathrm{N}-45^{\circ} \mathrm{N}$ during $1980-1999$ and 2081-2100 from seven IPCC AR4 models including CCSM3. Although $T_{\text {warm }}$ shows the largest changes and $\mathrm{T}_{\text {cold }}$ in $20 \mathrm{C} 3 \mathrm{M}$ only shows values less than 1 in the CCSM3 result, the differences across models are not very large. All models including CCSM3 consistently show the increase in $\mathrm{T}_{\text {warm }}$ and the decrease in $\mathrm{T}_{\text {cold }}$ in the $21 \mathrm{st}$ century compared to the present day. Especially, the maximum and minimum changes are consistently modeled in all $\mathrm{A} 2$ and $\mathrm{B} 1$ scenarios. Therefore, we can conclude that the projected changes in $\mathrm{T}_{\mathrm{warm}}$ and $\mathrm{T}_{\text {cold }}$ in CCSM3 in this study are reliable.

\section{Summary and discussion}

Given climate changes as represented by global (and/or regional) warming, the attendant changes in extremes have generated major concern in the scientific and public society. It is especially necessary for answering questions of public and decision makers related to the extreme vulnerability to know overall influence of various extremes as well as changes in individual extreme events. To satisfy these curiosities, we have developed new indices that integrate the influences of various existing extreme indices based on ETCCDMI. Our four indices are characterized by warm $\left(\mathrm{T}_{\text {warm }}\right)$, cold $\left(\mathrm{T}_{\text {cold }}\right)$, wet $\left(\mathrm{P}_{\text {wet }}\right)$, and dry $\left(\mathrm{P}_{\text {dry }}\right)$ extremes. The changes in these four indices have been examined using meteorological station observations for the period from the 1960s to the 2000s and model simulations using CCSM3 for 1900-2099.

In the observed data, three of the four extreme indices (all except $\mathrm{P}_{\text {wet }}$ ) show significant changes in northern regions of East Asia during the recent five decades. The temporal variations characterized by increase in $T_{\text {warm }}$ and $P_{\text {dry }}$ and decrease in $T_{\text {cold }}$ may be 
Fig. $13 \mathrm{~T}_{\text {warm }}$ indices (a) and $\mathrm{T}_{\text {cold }}$ indices (b) averaged over the region of $80^{\circ} \mathrm{E}-145^{\circ} \mathrm{E}$, $30^{\circ} \mathrm{N}-45^{\circ} \mathrm{N}$ during $1970-1999$ and 2081-2100 from various IPCC AR4 model runs. Black, light gray, dark gray, and white bars indicate the results from 20C3M, A2, A1B, and B1 scenarios

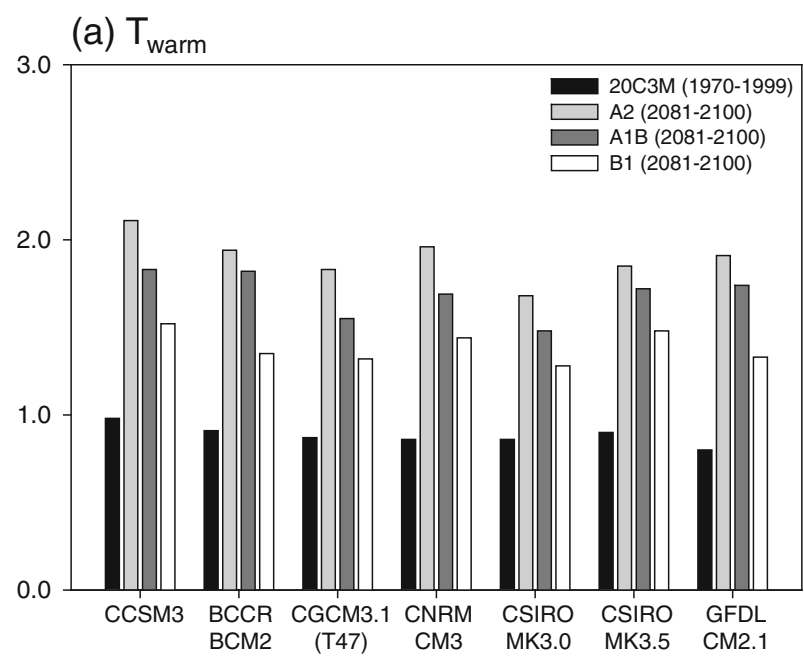

(b) $T_{\text {cold }}$

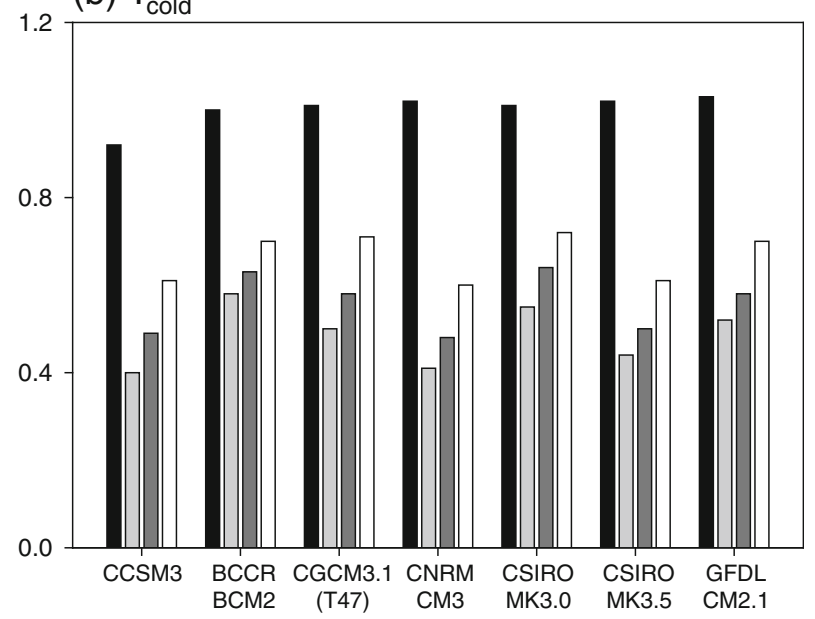

considered as consistent warming signals due to an anthropogenic climate changes. In particular, the results, which show the change in climatological average values of $T_{\text {warm }}$ is large in the southern region but the change in anomaly is large in the northern region, are line with previous studies concluding that the response to global warming is more obvious in the extratropics rather than the tropics (Dai et al. 2001). Correspondingly, $\mathrm{T}_{\text {cold }}$ decreases over the northern region and $\mathrm{P}_{\mathrm{dry}}$ increases, because over the northern inland region the available moisture is not sufficient despite the increase of temperature. The spatial variation of $\mathrm{P}_{\text {wet }}$ in the East Asia region presents a very sparse pattern and the temporal variation shows an insignificant pattern. However, in the area of Korea, observed $\mathrm{P}_{\text {wet }}$ has steadily increased during the past 40 years, consistent with previous studies that have examined the large increase of heavy rainfall over the same region in recent years.

In the model simulation using CCSM3 for 1900-2099, changes consistent with those in the observations are detected in the two temperature extremes $\left(T_{\text {warm }}\right.$ and $\left.T_{\text {cold }}\right)$ of the 20th century simulation, and consistent changes are continuously shown in the projection for the 21 st century. In the additional analysis of six IPCC AR4 models, the changes in $\mathrm{T}_{\text {warm }}$ and 
$\mathrm{T}_{\text {cold }}$ are projected in similar ranges to the CCSM3. From the results of both the historical and the model analyses, we can conclude that planning for increases in the vulnerability of the northern East Asia to the warm and dry extremes and in that of the Korea Peninsula to the wet extreme is strongly urged.

Indeed, many weather extreme events could be mitigated reasonably well by planning responses to the increased vulnerability of the East Asia region. In the absence of planning and proper policy, even a moderate weather event can become a disaster. It is thus important to assess the impact of extremes and establish the proper policy for minimizing the damage from disaster. By using our combined indices, people can easily understand the integrated impact of various extremes on their residential area, not taking care of the detail characteristics. In addition, these indices directly show how vulnerable the region is to extremes compared to other regions, since they are represented by the normalized value using the spatiotemporal mean of extremes over East Asia. Areas in the region shown to be vulnerable to greater dry extremes can for instance establish planning based on proven policies in currently dry areas, and so on. These indices can be helpful in preparing response to extreme weather by showing the vulnerability to the extremes with quantitative values.

Prior to applying these indices to public policy, we should note several limitations of the analysis. First, some indices obtained from ETCCDMI, especially the indices using a fixed threshold such as TR20 and SU25, may be insufficient to fully reflect the characteristics of extremes over East Asia. In addition, CDD is only one index for dry extreme in ETCCDMI. It is possible that we could confirm better-optimized indices for East Asia by applying this method on a sub-regional scale for East Asia. Second, to show the vulnerability more realistically, socio-economic factors such as population density and national economy should be considered as well. Finally, it must be noted that the conclusions of this study are limited to extreme weather events based on the indices represented by absolute variations in temperatures and precipitation. It is, however, dependent upon the perception of people affected by an event whether the event is considered as an extreme or not. For example, although the minimum temperature has increased in recent years, cold events suddenly occurring after consecutive warm days can be still considered as an extreme event by some people. Therefore, in further study, it is necessary to supplement our indices by considering even such a relative concept of the extremes as personal perception, to assess more realistically the extreme vulnerability.

Acknowledgements This research was performed under support of CATER 2006-4204. The first author was also supported by the BK21 project of Korean government.

Open Access This article is distributed under the terms of the Creative Commons Attribution Noncommercial License which permits any noncommercial use, distribution, and reproduction in any medium, provided the original author(s) and source are credited.

\section{References}

Alexander LV et al (2006) Global observed changes in daily climate extremes of temperature and precipitation. J Geophys Res 111:D05109

Collins WD et al (2006) The Community Climate System Model Version 3 (CCSM3). J Clim 19:2122-2143

Dai A, Wigley TML, Boville BA, Kiehl JT, Buja LE (2001) Climate of the twentieth and twenty-first centuries simulated by the NCAR Climate System Model. J Clim 14:485-519 
DeGaetano AT (1996) Recent trends in maximum and minimum temperature threshold exceedences in the northeastern Unites States. J Clim 9:1646-1660

Ding T, Qian W, Yan Z (2009) Changes in hot days and heat waves in China. Int J Climatol. doi:10.1002/ joc. 1989

Gong DY, Ho CH (2004) Intra-seasonal variability of wintertime temperature over East Asia. Theor Appl Climatol 24:131-144

Heino R, Brazdil R, Forland E, Tuomenvirta H, Alexandersson H, Beniston M, Pfister C, Rebetez M, Rosenhagen R, Rosner S, Wibig J (1999) Progress in the study of climate extremes in northern and central Europe. Climatic Change 42:151-181

Ho CH, Lee JY, Ahn MH, Lee HS (2003) A sudden change in summer rainfall characteristics in Korea during the late-1970s. Int J Climatol 24:131-144

Ho CH, Kim JH, Lau KM, Kim KM, Gong DY, Lee YB (2005) Interdecadal changes in heavy rainfall in China during the northern summer. Terr Atmos Ocean Sci 16:1163-1176

Iwasima T, Yamamoto R (1993) A statistical analysis of the extreme events: Long term trends of heavy precipitation. J Meteorol Soc Jpn 71:637-640

Karl TR, Knight RW, Easterling DR, Quayle RG (1996) Indices of climate change for the United States. Bull Am Meteorol Soc 77:279-292

Katz RW, Brown BG (1992) Extreme events in a changing climate: variability is more important than averages. Climatic Change 21:289-302

Kim J (2005) A projection of the effects of the climate change induced by increased $\mathrm{CO} 2$ on extreme hydrologic events in the western U.S. Climatic Change 68:153-168

Kim JH, Ho CH, Sui CH (2005) Circulation features associated with the record-breaking typhoon landfall on Japan in 2004. Geophys Res Lett 32:L14713. doi:10.1029/2005GL022494

Kim JH, Ho CH, Lee MH, Jeong JH, Chen D (2006) Large increase in heavy rainfall associated with tropical cyclone landfalls in Korea after the late 1970s. Geophys Res Lett 33:L18706. doi:10.1029/ 2006GL027430

Meehl GA et al (2007) Global climate projections. In: Solomon S et al (eds) Climate change 2007: the physical science basis. Cambridge University Press, Cambridge, pp 749-844

Nakicenovic N et al (2000) Special Report on Emission Scenarios, in A Special Report of Working Group III of the International Governmental Panel on Climate Change. Cambridge University Press, Cambridge, p 570

Osborn TJ, Jones PD (2000) Airflow influences on local climates: observed United Kingdom climate variations. Atmos Sci Lett 1:62-74

Park SK, Lee E (2007) Synoptic features of orographically enhanced heavy rainfall on the east coast of Korea associated with typhoon Rusa (2002). Geophys Res Lett 34:L02803. doi:10.1029/2006GL027395

Park TW, Ho CH, Yang S, Jeong SJ, Choi YS, Park SK, Song CK (2011) Different characteristics of cold day and cold surge frequency over East Asia in global warming situation. J Geophys Res 116:D12118. doi:10.1029/2011JD015369

Peterson TC, Manton MJ (2008) Monitoring changes in climate extremes: a tale of international collaboration. Bull Am Meteorol Soc 89:1266-1271

Ren G, Zhou Y, Chu Z, Zhou J, Zhang A, Guo J, Liu X (2008) Urbanization effects on observed surface air temperature trends in north China. J Clim 21:1333-1347

Trenberth KE et al (2007) Observations: surface and atmospheric climate change. In: Solomon S et al (eds) Climate change 2007: the physical science basis. Cambridge University Press, Cambridge, pp 235-336

Wang B, Ding Q, Jhun JG (2006) Trends in Seoul (1778-2004) summer precipitation. Geophys Res Lett 33 : L15803. doi:10.1029/2006GL026418

Wang X, Chen F, Hasi E, Li J (2008) Desertification in China: assessment. Earth Sci Rev 88:188-206

Yang X, Ding Z, Fan X, Zhou Z, Ma N (2007) Processes and mechanisms of desertification in northern China during the last 30 years, with a special reference to the Hunshandake Sandy Land, eastern Inner Mongolia. Catena 71:2-12

Zhai PM, Pan XH (2003) Trends in temperature extremes during 1951-1999 in China. Geophys Res Lett 30:1913. doi:10.1029/2003GL018004 